\title{
Risk-Based Multiobjective Optimal Seismic Design for RC Piers Using the Response Surface Method and NSGA-II
}

\author{
Sicong Hu $\mathbb{D}^{\mathrm{D}}$, Yixuan Zou, Yufeng Gai, Zheng Huang, and Guquan Song \\ School of Civil Engineering and Architecture, Nanchang University, Nanchang, China \\ Correspondence should be addressed to Sicong Hu; eric731hu@ncu.edu.cn
}

Received 25 May 2020; Revised 24 June 2020; Accepted 16 March 2021; Published 26 March 2021

Academic Editor: Moacir Kripka

Copyright (c) 2021 Sicong Hu et al. This is an open access article distributed under the Creative Commons Attribution License, which permits unrestricted use, distribution, and reproduction in any medium, provided the original work is properly cited.

\begin{abstract}
In this paper, a risk-based multiobjective optimal seismic design method for reinforced concrete (RC) piers is proposed. This method is used to determine the size and reinforcement ratios of piers to minimize the seismic risk of bridge systems and the construction cost of piers. The Pacific Earthquake Engineering Research- (PEER-) based probabilistic seismic risk assessment approach and the response surface method (RSM) are adopted to develop the seismic risk response surface model, which represents the relationship between the design parameters of piers and the seismic risk of bridge systems. The Pareto optimal solutions of piers are determined by applying an improved version of the nondominated sorting genetic algorithm (NSGA-II). As a case study, the proposed optimal seismic design method is applied to a continuous concrete box girder bridge. The optimal design schemes of piers according to two strategies are determined from the Pareto optimal solutions. The results show that the seismic risk response surface model can be used to accurately describe the relationship between the design parameters of piers and the seismic risk of bridge systems. The case study demonstrates the effectiveness of the proposed optimal seismic design method. The analysis of the Pareto optimal solutions allows designers to more rationally conduct the seismic design of piers.
\end{abstract}

\section{Introduction}

Bridges are important components of lifeline systems. Seismic damage of bridges may cause traffic disruption, entailing considerable social impacts and economic losses. Piers are one of the most crucial components of bridge systems. They need to support the superstructure, and they experience the seismic load from the superstructure to the foundation. However, piers are vulnerable components during earthquakes. In recent earthquakes, including the 1971 San Fernando earthquake, the 1989 Loma Prieta earthquake, and the 2008 Wenchuan earthquake, numerous bridges were destroyed because of the failure of piers [1]. Therefore, a reasonable seismic design of piers can effectively improve the safety of bridges during earthquakes.

In the late 20th century, performance-based seismic design (PBSD) was proposed [2, 3]. PBSD emphasizes the design of a structure that satisfies the predefined damage level under the designed level of seismic intensity. In previous studies, some optimal seismic design methods were proposed to realize PBSD. Li et al. [4] carried out a seismic optimization design for a continuous girder bridge under different earthquake levels. Zheng and Yuan [5] established a seismic optimization design method for piers using the response spectrum method. Sung and $\mathrm{Su}[6]$ proposed a fuzzy genetic optimization method for the PBSD of RC piers. Luo et al. [7] proposed a seismic design method for piers combining fuzzy logic control methods, neural network methods, and adaptive genetic algorithms. Fazli and Pakbaz [8] proposed a seismic optimization framework using linear modal dynamic demand analysis and nonlinear static capacity evaluation. Generally, nonlinear static procedures are commonly applied to obtain the seismic response of structures in these methods, but the accuracy may not satisfy the design requirements in many cases.

The Pacific Earthquake Engineering Research (PEER) Center proposed the probabilistic seismic risk analysis framework based on PBSD using the total probability theorem [9]. In this framework, nonlinear time history analysis can be adopted to obtain higher precision seismic responses. 
Moreover, various uncertain factors can be fully considered in this approach. However, the PEER-based seismic risk analysis framework is mainly applied to the seismic performance assessment of bridges [10-14]; few studies have applied it to the optimal seismic design of RC piers.

In this study, a risk-based multiobjective optimization seismic design method for RC piers is proposed. The seismic risk of bridges is obtained by using a PEER-based probabilistic seismic risk analysis framework. The RSM is applied to determine the relationship between the design parameters of piers and the seismic risk of bridge systems. The nondominated sorting genetic algorithm (NSGA-II) is used to obtain the Pareto optimal solutions of piers. Moreover, a continuous concrete box girder bridge is used as a case study and the optimal schemes of piers are determined using the proposed method.

\section{Risk-Based Optimal Seismic Design Method of RC Piers}

2.1. Optimization Functions. It is a task to determine reasonable section sizes and the amount of longitudinal and transverse reinforcements to ensure that a bridge system has a satisfactory seismic performance in the seismic design of piers. Generally, increasing the amount of material can improve the strength and ductility of piers and enhance the seismic performance of the bridge to some extent. However, this may cause the construction cost of piers to increase. Obviously, piers that have the lowest construction cost and can make the bridge have the best seismic performance are often more appealing to designers. According to the PBSD methodology, the seismic performance of a bridge can be quantified using the seismic risk of bridge systems. Seismic risk describes the probability that a structure will be damaged at a specific site. In this case, a lower seismic risk means that a structure has a better seismic performance. Therefore, the optimized seismic design of piers can be described as a multiobjective minimization problem. The objective functions are the seismic risk of bridge systems and the construction cost of the pier:

$$
\begin{aligned}
& \text { find } \mathbf{X}, \\
& \text { minimize } P(\mathbf{X}), C(\mathbf{X}) \text {, } \\
& \text { subject to } \mathbf{X}^{L} \leq \mathbf{X} \leq \mathbf{X}^{U},
\end{aligned}
$$

where $\mathbf{X}$ is the design parameter vector of piers; $P(\mathbf{X})$ and $C(\mathbf{X})$ are the seismic risk of bridge systems and the construction cost of piers, respectively; and $\mathbf{X}^{U}$ and $\mathbf{X}^{L}$ are the upper and lower bounds of the design parameter $\mathbf{X}$, respectively.

\subsection{Objective Functions}

2.2.1. Construction Cost of Piers. The construction cost of piers $C(\mathbf{X})$ can be expressed as follows:

$$
C=\left(C_{c}+C_{s}+C_{h}\right)=\left(c_{c}+c_{s} \rho_{s}+c_{h} \rho_{h}\right) V,
$$

where $C_{c}, C_{s}$, and $C_{h}$ are the costs of concrete, longitudinal reinforcements, and transverse reinforcements, respectively; $V$ is the volume of piers; $c_{c}, c_{s}$, and $c_{h}$ are the costs per volume of concrete, longitudinal reinforcement, and transverse reinforcement, respectively; $\rho_{s}$ and $\rho_{h}$ are the longitudinal reinforcement ratio and the transverse reinforcement ratio, respectively.

2.2.2. PEER-Based Seismic Risk Assessment of Bridges. According to the PEER-based seismic risk assessment framework, the seismic risk of a structure exceeding the defined damage state at a given site can be expressed as follows [9]:

$$
\begin{aligned}
P(\mathrm{DS}>\mathrm{d} s) & =\iint P(\mathrm{DS}>\mathrm{d} s \mid \mathrm{EDP} \\
& =\operatorname{edp}) \mid \mathrm{d} P(\mathrm{EDP}>\operatorname{edp} \mid \mathrm{IM} \\
& =\mathrm{im}) \| \mathrm{d} \lambda(\mathrm{IM}>\mathrm{im}) \mid,
\end{aligned}
$$

where $P(A>a \mid B=b)$ represents the conditional probability function of $A$ exceeding $a$ when $B$ reaches $b$; DS represents the damage state of a structure; EDP represents the engineering demand parameter; and IM represents the intensity measure of ground motion.

Three probabilistic analysis components are included in the equation: (1) probabilistic seismic capacity analysis, (2) probabilistic seismic demand analysis, and (3) probabilistic seismic hazard analysis. A common solution strategy is the convolution of probabilistic seismic capacity analysis and probabilistic seismic demand analysis. In this case, the results are obtained by seismic fragility analysis, and the seismic risk assessment of a structure can be simplified as follows:

$$
P(\mathrm{DS}>\mathrm{d} s)=\int P(\mathrm{DS}>\mathrm{d} s \mid \mathrm{IM}=\mathrm{im})|| \lambda^{\prime}(\mathrm{IM}>\mathrm{im}) \mid d(\mathrm{im}),
$$

the seismic fragility function describes the conditional failure probability of a component or structure that sustains a specific damage state for a given IM [10]. It can be described as follows:

$$
P(\mathrm{DS}>\mathrm{d} s \mid \mathrm{IM}=\mathrm{im})=P\left[\frac{S_{D}}{S_{C \mid \mathrm{d} s}} \mid \mathrm{IM}=\mathrm{im}\right],
$$

where $S_{D}$ is a structural seismic demand for a specific IM and $S_{C \mid \mathrm{d} s}$ is the structural seismic capacity corresponding to the given DS.

There are many uncertainties in the earthquake engineering. Generally, uncertainties can be divided into two types: aleatory and epistemic uncertainties [15, 16]. In particular, aleatory uncertainty includes the variability in ground motions, the variability in material properties, the geometry error of structures, and the size error of components during the construction. Epistemic uncertainty is caused by ignorance, such as the error of modelling. In the 
seismic fragility analysis, the above uncertainties are reflected in the seismic demand $S_{D}$ and seismic capacity $S_{C \mid \mathrm{d} s}$. In general, assuming $S_{D}$ and $S_{C \mid \mathrm{d} s}$ follow log-normal distributions, the seismic fragility function takes the following form:

$$
P(\mathrm{DS}>\mathrm{d} s \mid \mathrm{IM}=\mathrm{im})=\Phi\left[\frac{\lambda}{\sigma} \mid \mathrm{IM}=\mathrm{im}\right],
$$

where $\lambda$ and $\sigma$ are the median estimate and standard deviation of $\ln \left(S_{D} / S_{C \mid \mathrm{d} s}\right)$, respectively, and $\Phi(\cdot)$ is the standard normal cumulative distribution function.

Generally, $\lambda$ can be predicted by a log-linear model using the least-square method as follows:

$$
\lambda=a \ln (\mathrm{IM})+b,
$$

where $a$ and $b$ are the regression coefficients.

The dispersion $\sigma$ is determined by [11]

$$
\sigma=\sqrt{\frac{\sum_{i=1}^{N}\left[y_{i}-\lambda_{i}\right]^{2}}{(N-2)}},
$$

where $y_{i}$ and $\lambda_{i}$ are the actual and predicted values of a given IM, respectively, and $N$ is the number of simulations. $N-2$ represents the freedom degree of simulations when the loglinear model is adopted in the probabilistic seismic demand analysis.

The above theory is commonly used to develop the seismic fragility functions of components. In practice, the seismic damage of a single component cannot accurately reflect the damage of an entire bridge. Therefore, an approach to determine the seismic fragility functions of bridge systems was proposed by Nielson and DesRoches [12]. In general, the joint probabilistic seismic demand models are developed using the vector of the seismic response mean of each component and the correlation coefficient matrix of the seismic response of different components. Monte Carlo simulation is adopted to obtain random samples of the seismic capacity and seismic demand of bridge systems at different IMs for each damage state. The number of damage samples is counted, and a regression analysis is applied to estimate the seismic fragility functions of bridge systems.

The seismic hazard function has a nearly linear relationship on a log-log plot in the case of a small site seismic hazard [17]. Therefore, it can be expressed as follows:

$$
\lambda(\mathrm{IM})=k_{0} \times \mathrm{IM}^{-k},
$$

where $k_{0}$ and $k$ are the shape coefficients and can be calculated according to the following formula:

$$
\begin{aligned}
k & =\frac{\ln \left(\lambda_{1} / \lambda_{2}\right)}{\ln \left(\mathrm{IM}_{2} / \mathrm{IM}_{1}\right)}, \\
\ln \left(k_{0}\right) & =\frac{\left[\ln \left(\mathrm{IM}_{1}\right) \ln \left(\lambda_{2}\right)-\ln \left(\mathrm{IM}_{2}\right) \ln \left(\lambda_{1}\right)\right]}{\ln \left(\mathrm{IM}_{1} / \mathrm{IM}_{2}\right),}
\end{aligned}
$$

where $\mathrm{IM}_{1}$ and $\mathrm{IM}_{2}$ are the intensity values of two different ground motions and $\lambda_{1}$ and $\lambda_{2}$ are the corresponding annual exceedance probabilities.
2.3. Optimization Procedure of Piers Using the RSM and NSGA-II. As mentioned, the risk-based optimal seismic design of piers is a multiobjective optimization problem, and the seismic risk of bridge systems and the construction cost of piers are two conflicting objectives. In this case, the goal of the multiobjective optimization is not to obtain a single solution that minimizes all objective functions simultaneously but to obtain one set of solutions that cannot be improved in any of the objectives without degrading at least one of the other objectives. The set of solutions is defined as the Pareto optimal solutions. To obtain the Pareto optimal solutions, a high-performance multiobjective algorithm called the NSGA-II [18] is applied in this study.

In the NSGA-II method, a set of initial parent populations $P_{0}$ is randomly generated. Each individual in $P_{0}$ is ranked and selected based on the nondomination level, and each individual in the same rank is sorted and selected based on the crowded distance metric. New parent populations $P_{1}$ are selected by an elitism sort, and then, genetic operations, such as crossover and mutation, are performed to generate the child populations $Q_{1}$. The parent populations $P_{1}$ and the child populations $Q_{1}$ are combined to create new populations $R_{1}$. The fitness values are assigned to all individuals in $R_{1}$ by nondominated sorting and crowded distance sorting. Individuals with better fitness are selected by elitist sorting to generate new parent populations $P_{2}$. The process is repeated until the maximum generation is reached. Finally, individuals with first rank among the parents at $P_{\max }$ are the Pareto optimal solutions. A flowchart of the NSGA-II method is presented in Figure 1.

Generally, the values of the objective functions under different design parameters should be iteratively circulated in an optimization process. In this study, the construction cost of piers can be easily obtained using equation (2). However, the seismic risk of bridge systems should be obtained from nonlinear time history analysis according to the PEER-based seismic risk assessment approach. Obviously, the conventional iterative computation may be time-consuming and inefficient with the sizes of samples increasing in the optimization process. To improve the efficiency, an explicit function model between the design parameters of piers and the seismic risk of bridge systems is developed using the RSM before the optimization. In this case, only a small number of nonlinear time history analyses should be performed to develop the function model. The seismic risk of bridge systems under different design parameters of piers can be rapidly obtained from the function model without performing extra nonlinear time history analyses.

The RSM is used to develop an approximate functional relationship between a response variable and a set of design variables using mathematical and statistical techniques [19]. A general form of the RSM can be written as follows:

$$
z=f\left(x_{1}, x_{2}, \cdots, x_{p}\right)+\varepsilon
$$

where $z$ is the response variable; $x_{1}, x_{2}, \cdots, x_{p}$ are the input variables; $f(\cdot)$ is the real response function; and $\varepsilon$ is the residual factor associated with the experiments. 


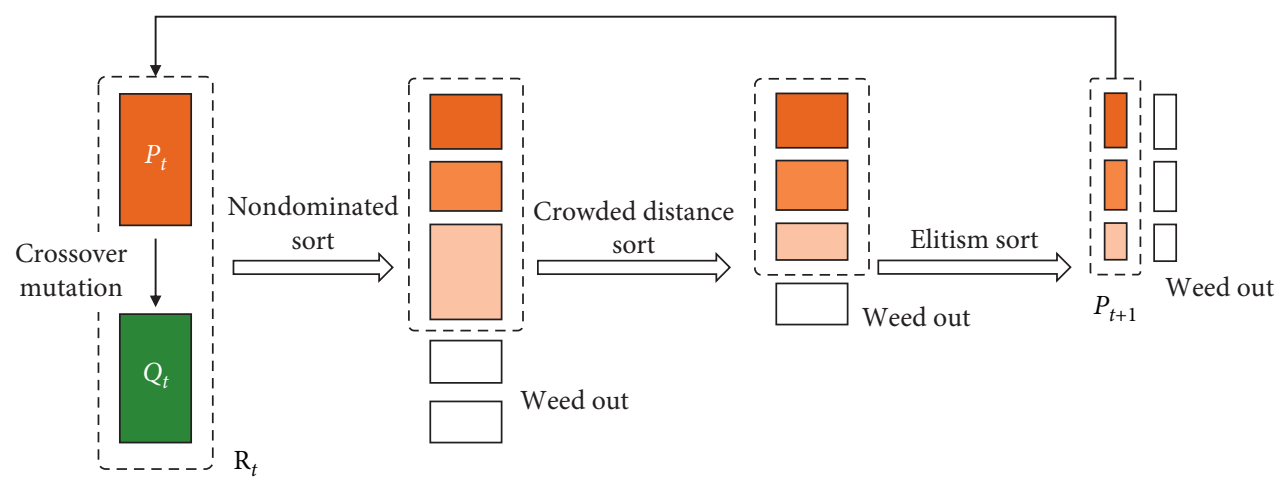

FIgUre 1: Flowchart of the NSGA-II method.

The RSM is commonly developed by performing a least squares regression analysis for a set of experimental points. The designs of the experimental techniques, such as full factorial design, central composite design, and orthogonal design, provide the necessary basis for selecting the experimental points. For an experimental design of three input parameters in three levels, the number of sample points using different experiment design methods is presented in Figure 2. Among these designs of experimental techniques, central composite design is widely applied because of the balance of precision and efficiency. For the $k$-factor problem, the central composite design consisting of one center point, $2 k$ axial points, and $2^{k}$ corner points is applied. Factor values are usually rescaled: corner points $= \pm 1$, center point $=0$, and axial points $= \pm \alpha$ (one factor) and 0 (the other factors).

The experimental points are then fitted through the RSM to find the relationship between the response variables and the input variables. The multivariate polynomial model is commonly applied to develop the response surface model because it can uniformly approximate any function models. Subsequently, multiple iterative is performed to determinate the final polynomial form. Specifically, the analysis of variance is carried out to determine the influence of various factor terms (such as the linear terms, high-order terms of each design parameter, and interaction terms between various design parameters). A linear model is regarded as the response surface model at first, and the accuracy of response surface model is checked. If the relationship between the response variables and the input variables cannot be accurately described by the linear model, other high-order terms and interaction terms are supplemented in the surface model until the prediction accuracy of the response surface method satisfies the requirements.

A common measure to determine if the RSM actually describes the experimental data is the determination coefficient $R^{2}$, and it can be described as follows:

$$
R^{2}=1-\frac{\sum_{i=1}^{m}\left(x_{i}-\widehat{x}_{i}\right)^{2}}{\sum_{i=1}^{m}\left(x_{i}-\bar{x}\right)^{2}},
$$

where $x_{i}$ and $\hat{x}_{i}$ are the $i$-th actual and simulated responses, respectively; $\bar{x}$ is the average of all actual responses; and $m$ is the number of data.
It is worth noting that the $R^{2}$ may be misleading with the increase in the number of input variables. In order to eliminate the effect, the adjusted coefficient of determination $R_{\text {adj }}^{2}$ is also considered for the adequate estimate. It can be calculated according to the following formula:

$$
R_{\mathrm{adj}}^{2}=1-\left(1-R^{2}\right)\left(\frac{m-1}{m-p}\right),
$$

where $p$ is the number of input variables.

Moreover, the root-mean-square error (RMSE) can also be used to check the accuracy of response surface model. It can be expressed as follows:

$$
\mathrm{RMSE}=\sqrt{\frac{1}{m-p} \sum_{i=1}^{m}\left(x_{i}-\hat{x}_{i}\right)^{2} .}
$$

For a perfect match, $R^{2}$ and $R_{\text {adj }}^{2}$ should be at least 0.9 and the RMSE should be close to 0 [20].

According to the NSGA-II and RSM, the flowchart of the risk-based optimal seismic design of RC piers is presented in Figure 3. Generally, several crucial steps are included in the process:

(1) The meaningful ranges of the design parameters of piers are determined, and bridge samples with various pier design parameters are generated using the experimental design techniques.

(2) The seismic risk of each bridge sample is determined using the PEER-based seismic risk assessment approach (equations (4) (10)).

(3) The appropriate form of response surface model is determined, and the coefficients are obtained by fitting to the seismic risk data points of bridge samples. Moreover, the adaptability test is performed to ensure the response surface model is accurate enough.

(4) Enough bridge samples with various pier design parameters are randomly generated and regarded as the initial parent populations. The seismic risk of each bridge sample is determined according to the seismic risk RSM, and the construction cost of the 


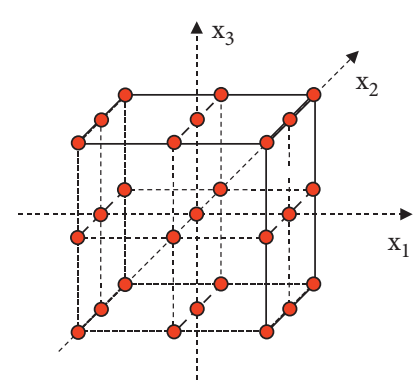

(a)

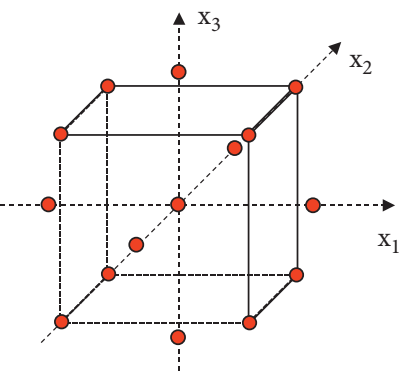

(b)

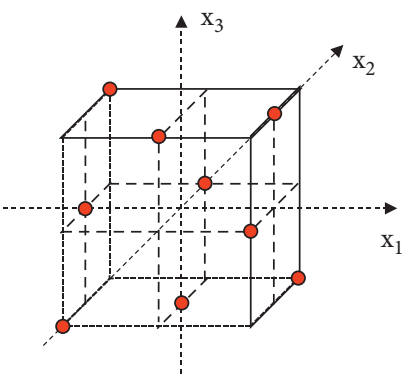

(c)

FIGURE 2: Experimental designs of three input parameters in three levels using (a) full factorial design, (b) central composite design, and (c) orthogonal design method.

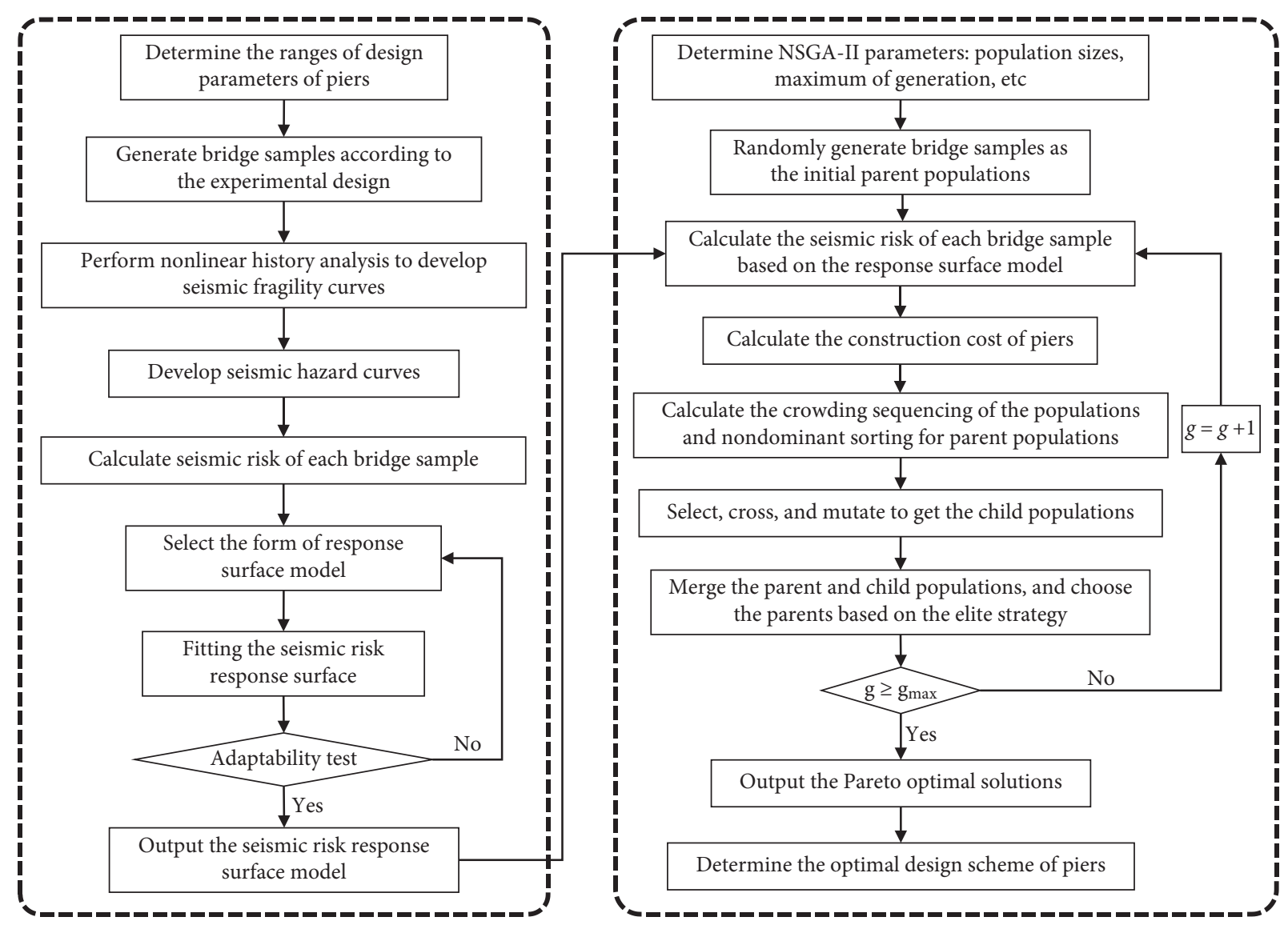

FIGURE 3: Flowchart of the risk-based optimal seismic design of piers using RSM and NSGA-II.

piers of each bridge sample is calculated by equation (2).

(5) The Pareto optimal solutions are obtained using the NSGA-II method.

(6) The optimal design scheme of piers is determined from the Pareto optimal solutions according to the specific optimization strategy.

2.4. Case Study and Bridge Modelling. A three-span continuous concrete box girder bridge is chosen as a case study for implementing the optimal seismic design procedure, as shown in Figure 4 . The spans of the bridge are $30 \mathrm{~m}$. The piers of the bridge are double columns with circular sections. The height of the piers is $10 \mathrm{~m}$. The diameter of the piers is $1.5 \mathrm{~m}$. The ratios of the longitudinal and transverse reinforcements of the cross section are $2.5 \%$ and $0.5 \%$, respectively. Four rubber bearings are arranged on the bent of each pier, and four PTFE elastomeric bearings are located on the abutment.

The case study bridge is simulated and analysed using OpenSees [21], an open-source computational platform developed and maintained in the University of California at Berkeley. Overall, the girder is modelled by the linear elastic 


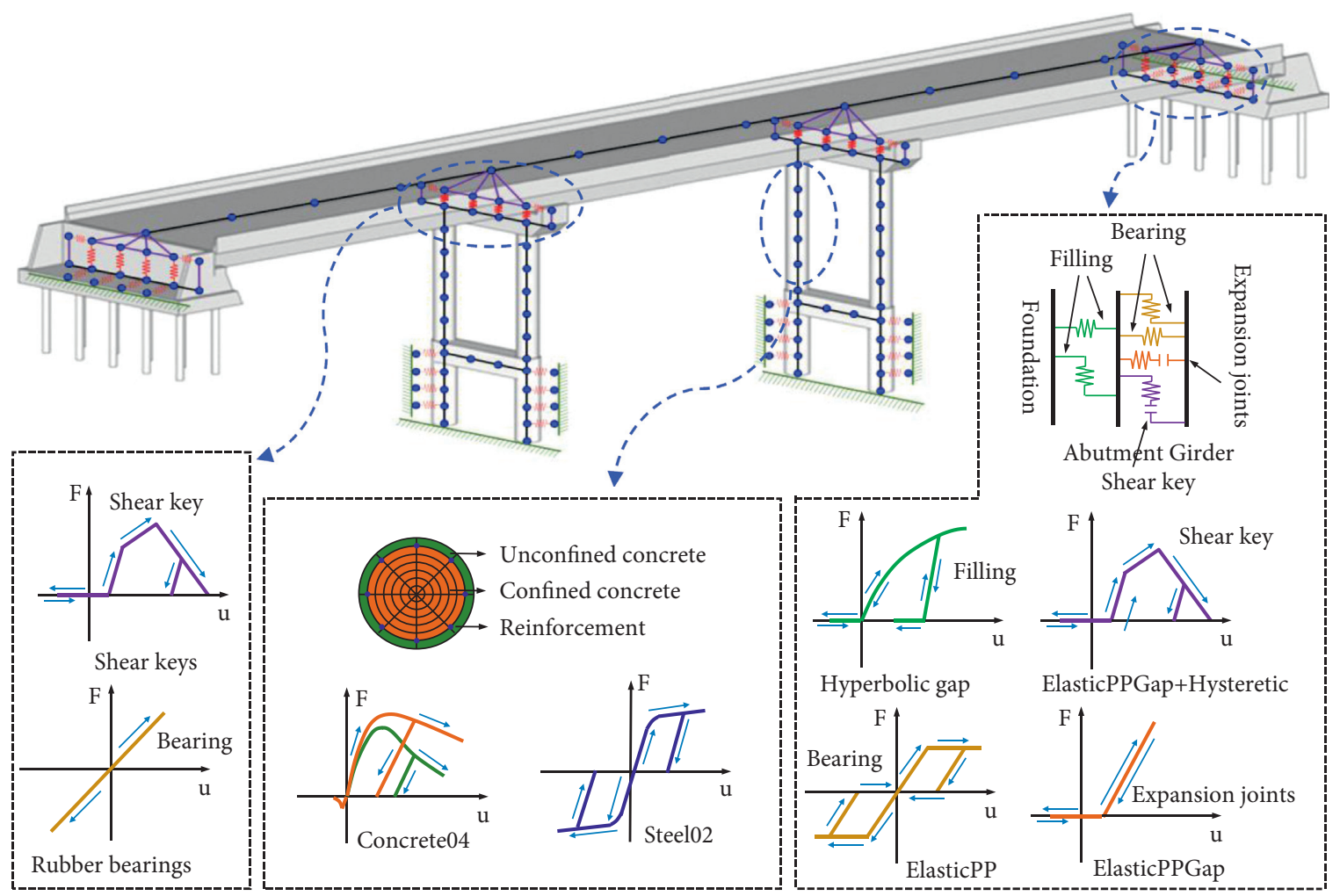

FIgURE 4: Case study three-span continuous concrete box girder bridge.

beam-column elements and the nonlinear beam-column element with fibre cross sections used to simulate the piers. The zero-length element with the Elastic and ElasticPP materials is used to simulate the rubber bearings and the PTFE bearings, respectively. Shear keys are simulated in parallel with the Hysteretic and ElasticPPGap materials. The expansion joints at the deck ends are modelled through the gap elements. Based on the model, the modal analysis is performed to determine the fundamental periods of the model. The first two periods of the bridge are $2.11 \mathrm{~s}$ and $1.51 \mathrm{~s}$, respectively.

As mentioned, it is necessary to fully consider various uncertainties in the seismic fragility assessment for a real engineering structure. However, this study focuses on proposing a risk-based optimal design framework for $\mathrm{RC}$ piers and the case study bridge is mainly used to elaborate the realization process of the optimal seismic design. Therefore, only the uncertainty of ground motions is included in the study. Therefore, 100 ground motions are selected from the PEER Ground Motion Database [22]. To consider the uncertainty of the ground motions, the selected ground motions include different source-to-site distances and magnitudes (Figure 5(a)): SMSR (small magnitude and small epicentre distances), SMLR (small magnitude and large epicentre distances), LMSR (large magnitude and small epicentre distances), LMLR (large magnitude and large epicentre distances), and NF (near field). The spectra acceleration at the geometric mean of the two periods in both the longitudinal and transverse directions $\left(S A_{G M}\right)$ is chosen as the intensity measure [23]. The linear spectra acceleration of 100 ground motions and the distribution of $S A_{G M}$ are shown in Figure 5(b).

2.5. Development of the Seismic Risk RSM. In this case study, the design parameters of the piers including the diameter $D$, the ratio of the longitudinal reinforcement $\rho_{s}$, and the ratio of the transverse reinforcement $\rho_{h}$ are considered. Before the optimal seismic design, the seismic risk RSM should be developed. The cross-sectional diameter of the piers is considered to range from $100 \mathrm{~cm}$ to $200 \mathrm{~cm}$, and the ratios of the longitudinal and transverse reinforcements are considered to range from $0.5 \%$ to $3 \%$. In total, 15 bridge samples are generated using the central composite design method. To obtain the seismic risk of each bridge sample, 100 nonlinear time history analyses are performed to determine the seismic demand model of the components. According to the definition of damage states in HAZUS-MH/MR3 [24], four-level damage states are adopted, namely, slight damage (SL), moderate damage (MO), extensive damage (EX), and complete damage (CO). Moreover, five kinds of components, including piers, shear keys, abutments, rubber bearings, and PTFE elastomeric bearings, are considered. The EDPs include the curvature ductility of the piers [12], the displacements of the PTFE elastomeric bearings, the shear strain of the rubber bearings [25], the deformation of the shear keys [26], and the longitudinal displacements of the abutments [27]. Moreover, two levels of ground motion with different annual exceedance probabilities (frequent earthquakes and rare earthquakes) in the Chinese seismic 


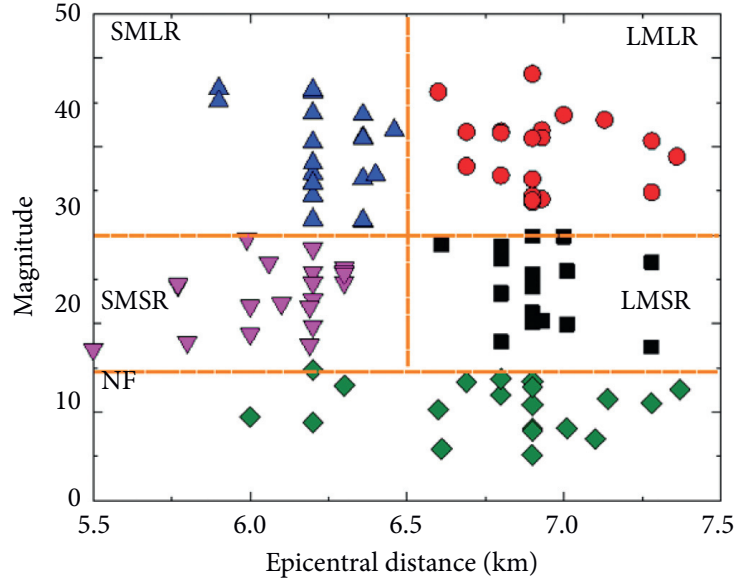

(a)

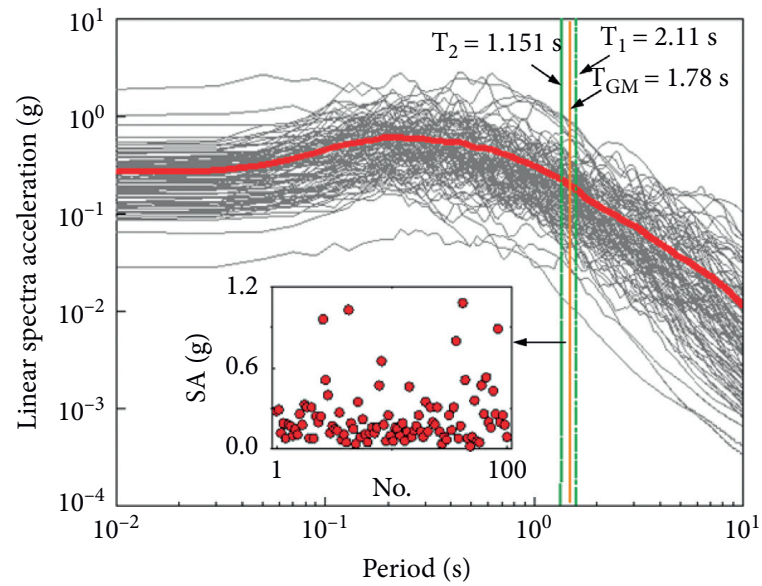

(b)

FIGURE 5: (a) Distribution of magnitude and epicentral distance of 100 ground motions; (b) linear spectra acceleration of 100 ground motions.

design code of highway bridges are adopted to determine the shape coefficients of the seismic hazard function [28]. The seismic risk of each bridge sample is logicized, and the quadratic polynomial is applied to develop the seismic risk
RSMs, as shown in equation (15a)-(15d). To verify the adequacy of the model, the test is performed, and the result is shown in Table 1 . The result implies a satisfactory representation of the process by the model.

$$
\begin{aligned}
& \ln (P \mid L S 1)=1.79+0.89 D+1.09 \rho_{s}+0.64 \rho_{h}-0.25 \rho_{s} D-0.09 \rho_{h} D-0.023 \rho_{s} \rho_{h}-0.29 D^{2}-0.14 \rho_{s}^{2}-0.12 \rho_{h}^{2}, \\
& \ln (P \mid L S 2)=-1.19+5.76 D+1.18 \rho_{s}+0.66 \rho_{h}-0.34 \rho_{s} D-0.09 \rho_{h} D-0.018 \rho_{s} \rho_{h}-1.06 D^{2}-0.124 \rho_{s}^{2}-0.18 \rho_{h}^{2}, \\
& \ln (P \mid L S 3)=4.6+2.2 D-0.18 \rho_{s}+0.28 \rho_{h}-0.017 \rho_{s} D-0.05 \rho_{h} D-0.01 \rho_{s} \rho_{h}-0.45 D^{2}-0.056 \rho_{s}^{2}-0.11 \rho_{h}^{2}, \\
& \ln (P \mid L S 4)=4.77+3.13 D-0.3 \rho_{s}+0.26 \rho_{h}-0.028 \rho_{s} D+0.066 \rho_{h} D+0.01 \rho_{s} \rho_{h}-0.743 D^{2}+0.09 \rho_{s}^{2}-0.11 \rho_{h}^{2} .
\end{aligned}
$$

2.6. Optimal Seismic Design of Piers. To calculate the construction cost of piers, the cost of materials is assumed to be $\$ 105 / \mathrm{m}^{3}$ for concrete and $\$ 7065 / \mathrm{m}^{3}$ for longitudinal and transversal reinforcements [29]. In the optimization process, 5000 initial populations are randomly generated, and the maximum generation number is set to 500 .

Figure 6 shows the distribution of the initial populations and the Pareto optimal solutions. A significant nonlinear relationship between the construction cost of piers and the seismic risk of bridge systems can be found from the Pareto optimal curves. The seismic risk of the bridge systems is more sensitive to the construction cost of the piers when the construction cost of the piers is low. The main reason is that the seismic performance of the piers is relatively weak compared with other components when the construction cost of the piers is low. In this case, the seismic damage of the piers may control the damage of the entire bridge.

However, the influence of the piers on the seismic risk of the bridge system is relatively small once the seismic performance of the piers exceeds that of most of the other components. Therefore, the influence of the piers on the seismic risk of the bridge system decreases as the construction cost of the piers increases.

The locations of the objective functions of the original scheme in the solution space are also presented in Figure 7. The original scheme (not on the Pareto optimal curves) indicates that the piers can be optimized without increasing the seismic risk of the bridge system and the construction cost of the piers. Depending on the relationship between the seismic risk of the piers and that of the other components in various damage states, the degree to which the piers can be optimized differs. Therefore, the distance from the original scheme to the Pareto optimal curves is significantly different in various damage states.

As mentioned, the Pareto solutions provide multiple design schemes of piers. Therefore, the reasonable optimal design strategies should be determined to choose the final design scheme from the Pareto solutions. Because the construction costs and seismic risk belong to different categories, it is difficult to find a strict optimization solution. In general, instead of optimizing all the objective functions, the designers or owners may optimize several objective 
TABLe 1: Accuracy test for the response surface model.

\begin{tabular}{lcccc}
\hline & Slight & Moderate & Extensive & Complete \\
\hline$R^{2}$ & 0.994 & 0.997 & 0.995 & 0.992 \\
$R_{\text {adj }}^{2}$ & 0.964 & 0.984 & 0.970 & 0.957 \\
RMSE & $8.66 \mathrm{E}-04$ & $3.93 \mathrm{E}-04$ & $5.12 \mathrm{E}-05$ & $3.16 \mathrm{E}-05$ \\
\hline
\end{tabular}

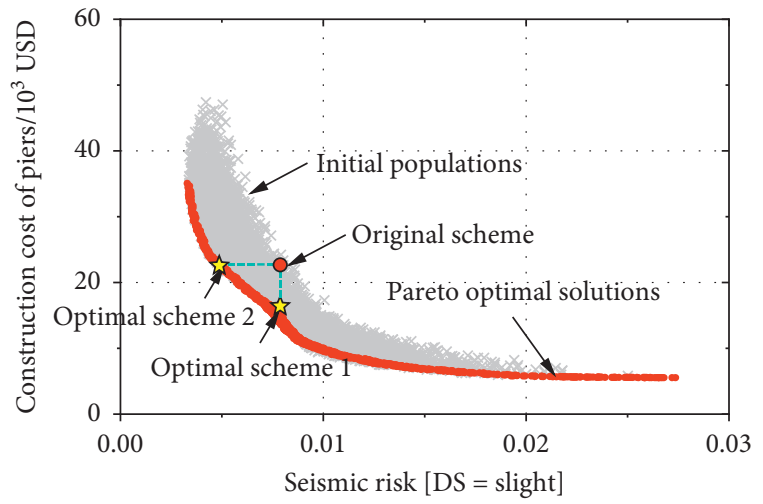

(a)

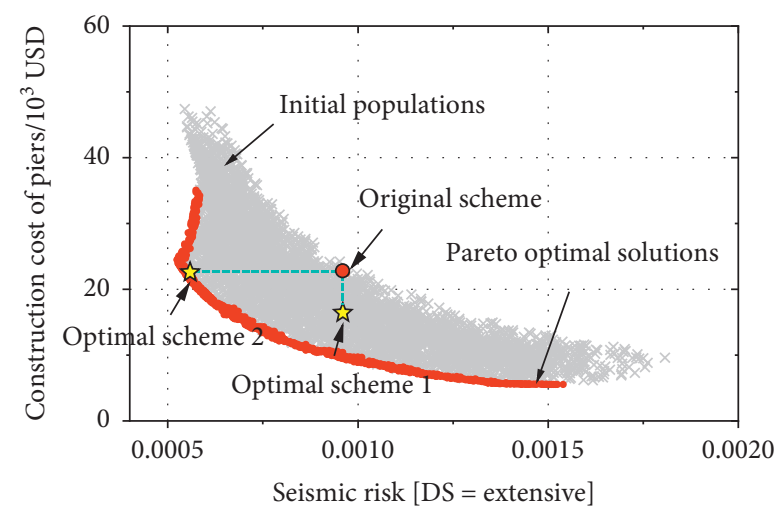

(c)

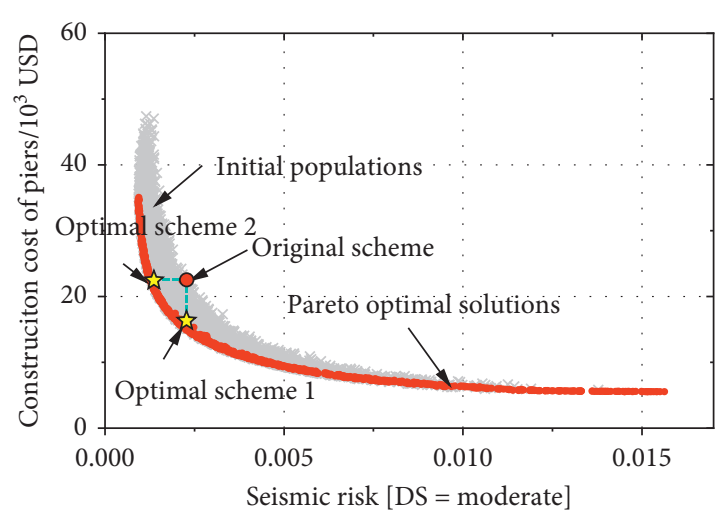

(b)

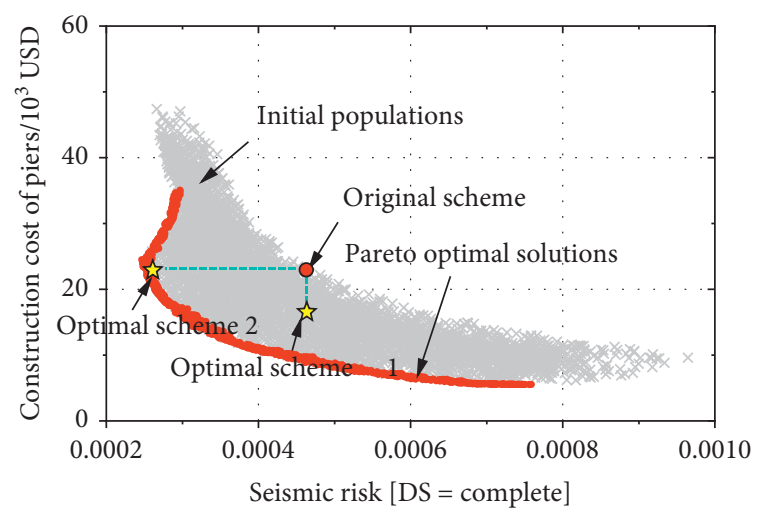

(d)

Figure 6: Initial populations and Pareto optimal solutions in the (a) slight, (b) moderate, (c) extensive, and (d) complete damage states.

functions while control the other objective functions within the limitations. For example, the designers are expected to maximize the seismic performance of bridges under the given investment/expenses while the owners are expected to minimize the investment as long as the bridges meet the basic/specification requirements. Therefore, two optimization strategies are considered to determine the optimal scheme of the piers: (1) optimization strategy 1 maintains the seismic risk of the bridge system in each damage state and minimizes the construction cost of the piers; (2) optimization strategy 2 minimizes the seismic risk of the bridge system in each damage state without increasing the construction cost of the piers. The optimal design parameters of the piers based on the two optimal strategies are listed in Table 2. The diameter of the piers increases, and the ratio of the longitudinal reinforcement decreases to $0.5 \%$ for the two optimal schemes. The main reason is that increasing both the diameter of the piers and the ratio of the longitudinal reinforcement can enhance the bending strength of the piers, entailing a decrease in the seismic risk of the bridge system in slight and moderate damage states. Because of the relatively low cost of concrete, it is more economical to increase the diameter of the piers. Moreover, the transverse reinforcement can effectively increase the ductility level of the piers and reduce the seismic risk of the bridge system in extensive and complete damage states. Therefore, the ratio of the transverse reinforcement increases for the two optimal schemes. Comparing the original and optimal schemes, the construction cost of the piers can be reduced by nearly $26 \%$ for optimal scheme 1 and the seismic risk of the bridge system in the four damage states can be decreased by $35 \%$ $41 \%$ for optimal scheme 2 . Obviously, the proposed optimal design method can effectively decrease the seismic risk of bridge systems or the construction cost of piers.

Figure 7 presents the seismic fragility curves of various components and a bridge system with different pier design schemes. In theory, the shear keys and bearings on the bent are in series with the piers. Therefore, the seismic fragility of the 

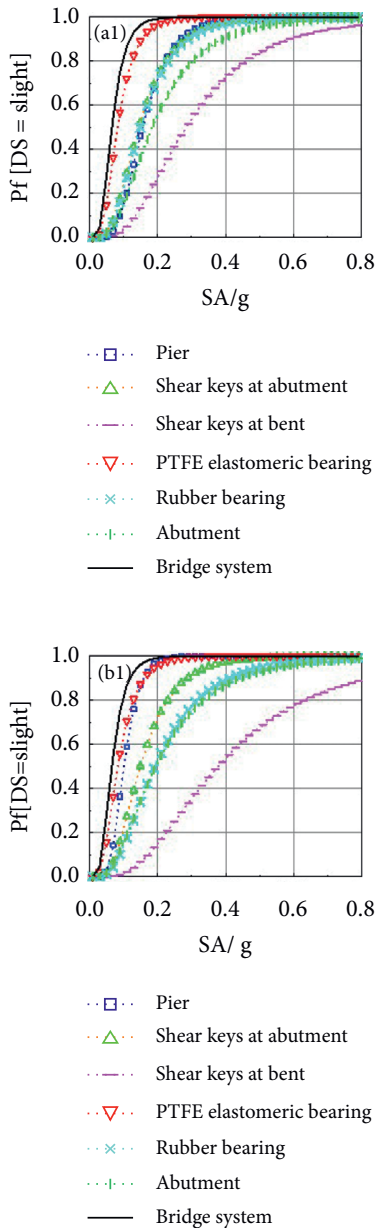

_ Bridge system
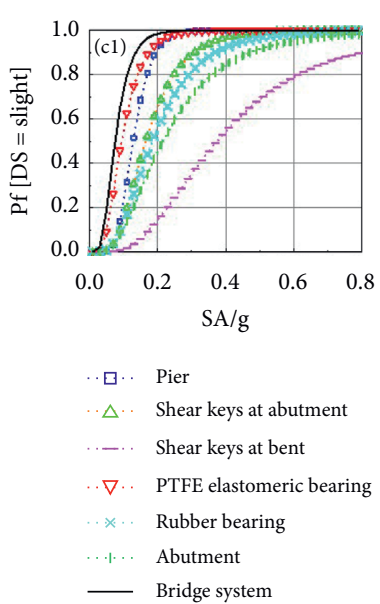
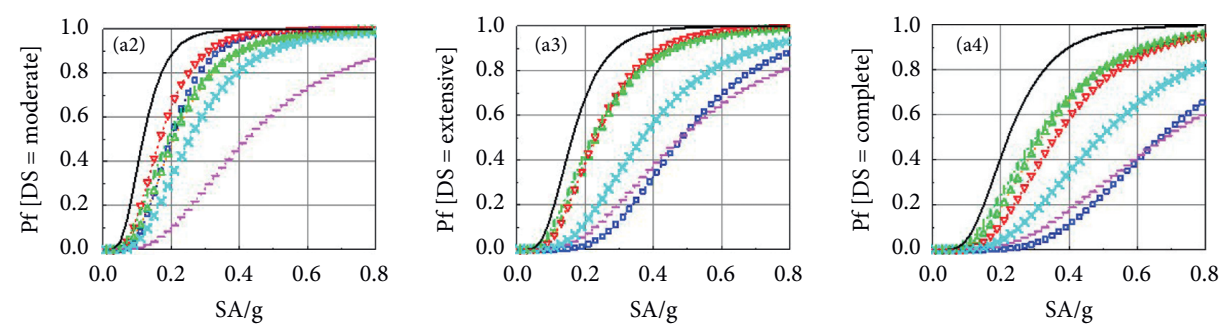

$$
\begin{array}{ll}
\cdots \square \cdots & \text { Pier } \\
\cdots \triangle \cdots & \text { Shear keys at abutment } \\
\cdots-\cdots & \text { Shear keys at bent } \\
\cdots \nabla \cdots & \text { PTFE elastomeric bearing } \\
\cdots \cdots & \text { Rubber bearing } \\
\cdots \cdots & \text { Abutment } \\
-\quad & \text { Bridge system }
\end{array}
$$

(a)
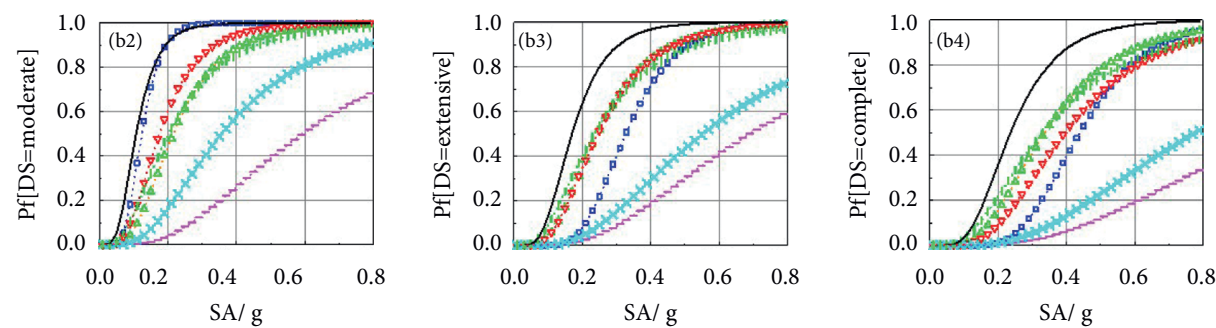

$$
\begin{aligned}
& \cdot \square \cdot \text { Pier } \\
& \text { - } \triangle \text {.. Shear keys at abutment } \\
& \text {._. Shear keys at bent } \\
& \nabla \cdot \quad \text { PTFE elastomeric bearing } \\
& \text { Rubber bearing } \\
& \text { Abutment } \\
& \text { Bridge system }
\end{aligned}
$$

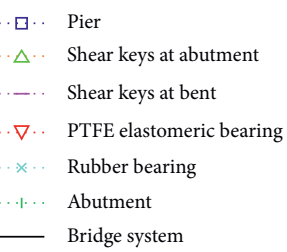

(b)
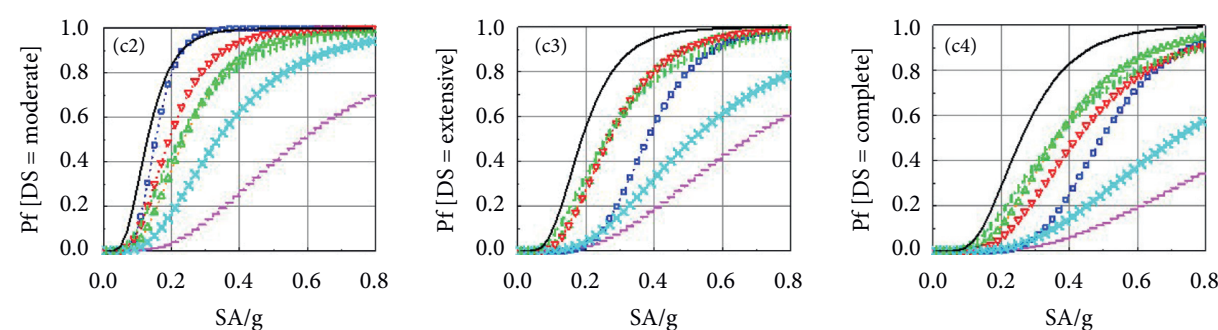

$$
\begin{array}{ll}
\cdots \square \cdot & \text { Pier } \\
\cdots \triangle \cdots & \text { Shear keys at abutment } \\
\cdots-\cdots & \text { Shear keys at bent } \\
\cdots \nabla \cdots & \text { PTFE elastomeric bearing } \\
\cdots \rtimes & \text { Rubber bearing } \\
\cdots \cdots & \text { Abutment } \\
& \text { Bridge system }
\end{array}
$$

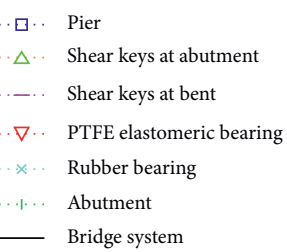

๑. . Pier

$\triangle \quad$ Shear keys at abutment

..... Shear keys at bent

$\cdot \nabla$. PTFE elastomeric bearing Rubber bearing Abutment

Bridge system
… Pier

$\triangle$. Shear keys at abutment

..... Shear keys at bent

$\cdots \quad$. PTFE elastomeric bearing

*.. Rubber bearing Abutment

Bridge system

(c)

FIGURE 7: Seismic fragility curves of various components and a bridge system with different design schemes of piers: (a) original scheme; (b) optimal scheme 1; and (c) optimal scheme 2 in the (1) slight, (2) moderate, (3) extensive, and (4) complete damage states.

shear keys and bearings on the bent will remarkably interact with that of the piers. If the seismic fragility of the piers increases, the inertial forces in the system will decrease, entailing a reduction in the seismic fragility of the shear keys and bearings on the bent. In contrast, an increase in the seismic fragility of the piers will increase the deformation of the girder to a certain extent, resulting in a slight increase in the seismic fragility of the abutment, shear keys, and bearings on the abutment. It can be seen that the optimization of the piers will affect the damage of all components by different levels. Instead of minimizing the seismic damage of piers, the optimal method proposed in this study aims to minimize the seismic damage of 
TABle 2: Design parameters and objective functions of piers with different design schemes.

\begin{tabular}{lcccccccc}
\hline Project & $D$ & $\rho_{s}$ & $\rho_{h}$ & $C$ & P|SL & P|MO & P|EX & P|CO \\
\hline Original scheme & $150 \mathrm{~cm}$ & $2.5 \%$ & $0.50 \%$ & $\$ 22400$ & 0.0079 & 0.0022 & 0.00097 & 0.00046 \\
Optimal scheme 1 & $167 \mathrm{~cm}$ & $0.5 \%$ & $1.70 \%$ & $\$ 16600$ & 0.0079 & 0.0020 & 0.00068 & 0.00031 \\
Optimal scheme 2 & $194 \mathrm{~cm}$ & $0.5 \%$ & $1.54 \%$ & $\$ 22400$ & 0.0051 & 0.0013 & 0.00057 & 0.00027 \\
\hline
\end{tabular}

bridge systems by balancing the seismic performance of various components.

\section{Conclusion}

This study presents a risk-based multiobjective optimal seismic design method for RC piers using the RSM and NSGA-II. The optimal scheme for piers that minimizes the seismic risk of bridges and the construction cost of piers can be obtained according to the method. A case study bridge is selected to perform a seismic optimization analysis. The main conclusions can be summarized as follows:

(1) The seismic risk RSM can be used to accurately describe the relationship between the design parameters of piers and the seismic risk of bridge systems. The efficiency of the multiobjective optimal process can be improved using the seismic risk RSM.

(2) A significant nonlinear relationship between the construction cost of piers and the seismic risk of bridge systems can be found from the Pareto optimal curves. The influence of piers on the seismic risk of bridge systems depends on the relationship between the seismic risk of piers and that of the other components.

(3) The proposed optimal seismic design method minimizes the construction cost of piers or the seismic risk of bridge systems by balancing the seismic performances of the various components. The case study demonstrates the effectiveness of the optimal method. The Pareto optimal solutions describe an optimal relationship between the construction cost of piers and the seismic risk of bridge systems in different damage states. This method can be a useful seismic design tool for decision-makers.

\section{Data Availability}

The data used to support the findings of this study are available from the corresponding author upon request.

\section{Conflicts of Interest}

The authors declare that they have no conflicts of interest.

\section{Acknowledgments}

This study was supported by the Natural Science Foundation of Jiangxi Province of China (No. 20192BAB216033), the China Postdoctoral Science Foundation (No. 2020M671972), and the
National Innovation and Entrepreneurship Training Program for Undergraduate of China (No. 201910403021).

\section{References}

[1] Z. Wang and G. C. Lee, "A comparative study of bridge damage due to the Wenchuan, Northridge, Loma Prieta and San Fernando earthquakes," Earthquake Engineering and Engineering Vibration, vol. 8, no. 2, pp. 251-261, 2009.

[2] K. A. Porter, "An overview of PEER's performance-based earthquake engineering methodology," in Proceedings of Ninth International Conference on Applications of Statistics and Probability in Civil Engineering, San Francisco, CA, USA, 2003.

[3] M. J. N. Priestley, "Performance based seismic design," Bulletin of the New Zealand Society for Earthquake Engineering, vol. 33, no. 3, pp. 325-346, 2000.

[4] J. Li, W. Yuan, and L. Fan, "Optimization design of continuous girder bridge with seismic isolation system," China Civil Engineering Journal, vol. 31, no. 3, pp. 47-54, 1998.

[5] Y. Zheng and W. Yuan, "The ductile seismic optimization design of circular single-column pier of reinforced concrete regular bridge based on the GA-RS," Journal of Vibration and Shock, vol. 29, no. 3, pp. 81-84, 2010.

[6] Y.-C. Sung and C.-K. Su, "Fuzzy genetic optimization on performance-based seismic design of reinforced concrete bridge piers with single-column type," Optimization and Engineering, vol. 11, no. 3, pp. 471-496, 2010.

[7] X. Luo, Y. Xiang, and T. Wu, "Seismic optimization design method based on performance for single-column piers," China Journal of Highway and Transport, vol. 27, no. 7, pp. 85-90, 2014.

[8] H. Fazli and A. Pakbaz, "Performance-based seismic design optimization for multi-column RC bridge piers, considering quasi-isolation," International Journal of Optimization in Civil Engineering, vol. 8, no. 4, pp. 525-545, 2018.

[9] J. Moehle and G. G. Deierlein, "A framework methodology for performance-based earthquake engineering," in Proceedings of the 13th World Conference on Earthquake Engineering, vol. 679, Vancouver, Canada, 2004.

[10] E. Choi, R. DesRoches, and B. Nielson, "Seismic fragility of typical bridges in moderate seismic zones," Engineering Structures, vol. 26, no. 2, pp. 187-199, 2004.

[11] S. Mangalathu, J.-S. Jeon, J. E. Padgett, and R. DesRoches, "ANCOVA-based grouping of bridge classes for seismic fragility assessment," Engineering Structures, vol. 123, pp. 379-394, 2016.

[12] B. G. Nielson and R. DesRoches, "Seismic fragility methodology for highway bridges using a component level approach," Earthquake Engineering \& Structural Dynamics, vol. 36, no. 6, pp. 823-839, 2007.

[13] R. G. Lee and A. S. Kiremidjian, Uncertainty and Correlation in Seismic Risk Assessment of Transportation Systems, Pacific 
Earthquake Engineering Research Center, Richmond, CA, USA, 2007.

[14] J. Ghosh and J. E. Padgett, "Probabilistic seismic loss assessment of aging bridges using a component-level cost estimation approach," Earthquake Engineering \& Structural Dynamics, vol. 40, no. 15, pp. 1743-1761, 2011.

[15] J. Zhang, M. Xiao, L. Gao, and J. Fu, "A novel projection outline based active learning method and its combination with Kriging metamodel for hybrid reliability analysis with random and interval variables," Computer Methods in Applied Mechanics and Engineering, vol. 341, pp. 32-52, 2018.

[16] J. Zhang, M. Xiao, L. Gao, and S. Chu, "A combined projection-outline-based active learning Kriging and adaptive importance sampling method for hybrid reliability analysis with small failure probabilities," Computer Methods in Applied Mechanics and Engineering, vol. 344, pp. 13-33, 2019.

[17] C. A. Cornell, F. Jalayer, R. O. Hamburger, and D. A. Foutch, "Probabilistic basis for 2000 SAC federal emergency management agency steel moment frame guidelines," Journal of Structural Engineering, vol. 128, no. 4, pp. 526-533, 2002.

[18] K. Deb, A. Pratap, S. Agarwal, and T. Meyarivan, "A fast and elitist multiobjective genetic algorithm: nsga-II," IEEE Transactions on Evolutionary Computation, vol. 6, no. 2, pp. 182-197, 2002.

[19] G. E. P. Box and K. B. Wilson, "On the experimental attainment of optimum conditions," Journal of the Royal Statistical Society: Series B (Methodological), vol. 13, no. 1, pp. 1-38, 1951.

[20] M. Papila and R. T. Haftka, "Response surface approximations: noise, error repair, and modeling errors," AIAA Journal, vol. 38, no. 12, pp. 2336-2343, 2000.

[21] F. McKenna, G. Fenves, and M. Scott, Open System for Earthquake Engineering Simulation, Pacific Earthquake Engineering Research Center: NGA Database, Richmond, CA, USA, 2000, http://peer.berkeley.edu/nga/.

[22] Pacific Earthquake Engineering Research Center, PEER-NGA, Pacific Earthquake Engineering Research Center: NGA Database, Pacific Earthquake Engineering Research Center, Richmond, CA, USAhttp://peer.berkeley.edu/nga/.

[23] B. G. Nielson, "Analytical fragility curves for highway bridges in moderate seismic zones," Ph.D. Thesis, Georgia Institute of Technology, Atlanta, Georgia, 2005.

[24] HAZUS-MH MR3, "Multi-hazard loss estimation methodology earthquake model," Federal Emergency Management Agency, Washington, USA, Technical Manual, 2003.

[25] S. C. Hu, L. H. Wang, L. F. Li et al., "Time-dependent seismic fragility assessment of offshore bridges subject to non-uniform chloride-induced corrosion," China Civil Engineering Journal, vol. 52, no. 4, pp. 62-71+97, 2019.

[26] H. Tang, J. Li, and C. Shao, "Seismic performance of small and medium span girder bridges with plate type elastomeric pad bearings in the transverse direction," China Journal of Highway and Transport, vol. 29, no. 3, pp. 55-65, 2016.

[27] W. P. Wu, "Seismic fragility of reinforced concrete bridges with consideration of various sources of uncertainty," Ph.D. Thesis, Hunan university, Changsha, China, 2015.

[28] Ministry of Transport of the People's Republic of China, Guidelines for Seismic Design of Highway Bridges, China Communication Press, Beijing, China, 2008.

[29] M. J. Esfandiari, G. S. Urgessa, S. Sheikholarefin, and S. H. D. Manshadi, "Optimum design of 3D reinforced concrete frames using DMPSO algorithm," Advances in Engineering Software, vol. 115, pp. 149-160, 2018. 